\title{
BMJ Open Satisfaction with rehabilitative health care services among German and non- German nationals residing in Germany: a cross-sectional study
}

\author{
Patrick Brzoska, ${ }^{1}$ Odile Sauzet, ${ }^{2}$ Yüce Yilmaz-Aslan, ${ }^{2}$ Teresia Widera, ${ }^{3}$ \\ Oliver Razum ${ }^{2}$
}

To cite: Brzoska P, Sauzet 0, Yilmaz-Aslan Y, et al. Satisfaction with rehabilitative health care services among German and non-German nationals residing in Germany: a cross-sectional study. BMJ Open 2017;7:e015520. doi:10.1136/ bmjopen-2016-015520

- Prepublication history for this paper is available online. To view these files please visit the journal online (http://dx.doi. org/10.1136/bmjopen-2016015520).

Received 13 December 2016 Revised 13 May 2017

Accepted 16 June 2017

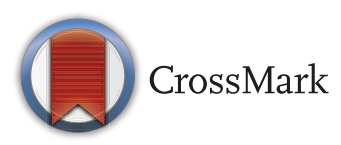

${ }^{1}$ Faculty of Behavioral and Social Sciences, Chemnitz University of Technology, Chemnitz, Germany ${ }^{2}$ School of Public Health, Department of Epidemiology \& International Public Health, Bielefeld University, Bielefeld, Germany

${ }^{3}$ Social Medicine and Rehabilitation, Section Rehabilitation Research, German Statutory Pension Insurance Scheme (Deutsche Rentenversicherung Bund, Geschäftsbereich Sozialmedizin und Rehabilitation, Bereich Reha-Wissenschaften), Berlin, Germany

\section{Correspondence to} Professor Patrick Brzoska; patrick.brzoska@soziologie.tuchemnitz.de

\section{ABSTRACT}

Objectives Rehabilitation following medical conditions is largely offered as in-patient service in Germany. Foreignnational residents use rehabilitative services less often than Germans and attain less favourable treatment outcomes. These differences are independent of demographic, socioeconomic and health characteristics. Satisfaction with different aspects of rehabilitative care presumably affects the effectiveness of rehabilitative services. We compared the degree of satisfaction with different domains of the rehabilitative care process between Germans and nonGerman nationals residing in Germany.

Methods We used data from a cross-sectional rehabilitation patient survey annually conducted by the German Statutory Pension Insurance Scheme. The sample comprises 274513 individuals undergoing medical rehabilitation in 642 hospitals during the years 2007-2011. Participants rated their satisfaction with different domains of rehabilitation on multiitem scales. We dichotomised each scale to low/moderate and high satisfaction. For each domain, a multilevel adjusted logistic regression analysis was conducted to examine differences in the levels of satisfaction between German and non-German nationals. Average marginal effects (AMEs) and $99.5 \% \mathrm{Cl}$ were computed as effect estimates. AMEs represent differences in the probability for the occurrence of the outcome.

Results Turkish nationals had a higher probability for being less satisfied with most aspects of their rehabilitation, with AMEs ranging between 0.05 (99.5\% $\mathrm{Cl} 0.00$ to 0.09$)$ for 'satisfaction with psychological care' and 0.11 (99.5\% Cl 0.08 to 0.14 ) for 'satisfaction with treatments during rehabilitation'. Patients from former Yugoslavia and from Portugal/Spain/Italy/Greece were as satisfied as Germans with most aspects of their rehabilitation.

Conclusions Turkish nationals are less satisfied with their rehabilitative care than other population groups. This may be attributable to the diversity of the population in terms of its expectations towards rehabilitation. Rehabilitative care institutions need to provide services that are sensitive to the needs of all clients. Diversity management can contribute to this process.

\section{INTRODUCTION}

The populations of many European countries comprise large proportions of foreign
Strengths and limitations of this study

- The study is the first to compare the satisfaction with rehabilitative care between German and nonGerman nationals residing in Germany.

- We use data from a national sample survey of hospitals that provide rehabilitation for individuals of working age.

- The survey is conducted in German language, so our investigation, despite adjustment, is prone to selection bias and possibly underestimates differences in healthcare satisfaction between Germans and non-Germans.

nationals. ${ }^{1}$ In Germany, about $10 \%$ of the 81 million inhabitants have no German citizenship. Turkish nationals form the largest population group of non-German nationals, totalling about 1.5 million individuals. Other large population groups of foreign nationals in Germany are individuals with a nationality from a Former Yugoslavian country (about 1 million) and from one of the South European countries Portugal, Spain, Italy or Greece (about 1.1 million). ${ }^{2}$ Many of these individuals came to Germany as labour migrants and settled in the country together with their families. Foreign nationals differ from the majority populations of the countries they reside in with respect to many health aspects. ${ }^{34}$ In terms of their occupational health, they are at a higher risk of occupational accidents and diseases and at a higher risk of retirement due to disability. ${ }^{5-7}$ In part, this results from disadvantageous environmental and social factors they are exposed to such as poor working conditions and a lower socioeconomic status. ${ }^{49}$

Tertiary preventive health services such as medical rehabilitation are particularly important for this population group because they are able to prevent (work-related) 
invalidity and to mitigate the consequences of chronic diseases. ${ }^{10}$ In Germany, different healthcare institutions are in charge of covering the costs for rehabilitative care. Rehabilitations for individuals in working age are covered by the German Statutory Pension Insurance Scheme ('Deutsche Rentenversicherung'), which accounts for about two-thirds of all rehabilitations provided in Germany. ${ }^{11}$ In over $90 \%$ of all cases, rehabilitation in Germany is usually conducted by means of 3-week in-patient programmes carried out in specialised hospitals. ${ }^{12}$ Studies from Germany show that non-German nationals use rehabilitation services less often than Germans despite being equally entitled to use these services free or for a low charge (depending on the type of insurance a contribution of up to $€ 10$ per day of treatment has to be made by patients) as part of their social insurance ${ }^{13}$ (this does not apply to refugees and asylum seekers who are initially only entitled to receive free emergency care ${ }^{1415}$ ). In addition, those non-Germans who make use of rehabilitation programmes benefit less from these services than their German counterparts even after adjusting for demographic and socioeconomic factors as well as disease profiles. This is particularly true for Turkish nationals and becomes evident in a lower occupational performance, a higher risk of disability retirement after rehabilitation ${ }^{13} 16$ and a lower self-perceived effectiveness of rehabilitative treatment. ${ }^{17}$ Similar observations were made in the Netherlands. ${ }^{18} 19$

Qualitative studies focusing on potential barriers that non-German nationals may encounter in the rehabilitative system suggest that the satisfaction with different components of the rehabilitative care process has a large impact on the effectiveness of rehabilitation in this population group. ${ }^{20-22}$ This is in line with research findings showing that the satisfaction with healthcare services is positively associated with coping with disease and health outcomes. ${ }^{23-27}$ In Germany and other Western countries, migrants, on average, have a lower satisfaction with different primary and secondary healthcare services than non-migrants. ${ }^{28-31}$ Little is known about the satisfaction of migrants concerning rehabilitative care services. The aim of the present study was to compare the degree of satisfaction with different aspects of the rehabilitative care process between German and non-German nationals. Since patient satisfaction results from the subjective evaluation of the gap between patients' own expectations towards healthcare and their perceptions of actual healthcare reality, ${ }^{32}$ knowledge about possible differences in the satisfaction between both populations can help to adjust rehabilitative care to the objective and subjective needs of migrants. Although the German system of rehabilitation differs from that of other countries ${ }^{12}$ insights into the satisfaction of non-Germans with respect to different aspects of healthcare provision can also contribute to devising migrant-sensitive healthcare in other settings.
MATERIALS AND METHODS

\section{Data}

To examine the degree of satisfaction with different aspects of rehabilitation, we drew on data from a cross-sectional and representative rehabilitation patient survey ('Rehabilitandenbefragung') annually conducted by the German Statutory Pension Insurance Scheme among individuals who completed rehabilitation granted by this organisation. The rehabilitation survey is conducted as part of an external quality assurance programme implemented by the German Statutory Pension Insurance Scheme for institutions providing rehabilitative care. On a monthly basis, 20 individuals from each of the 642 hospitals who completed rehabilitation are selected at random and surveyed at home by means of a postal German-language self-administered questionnaire 8-12 weeks after their discharge from the rehabilitation hospital. The survey is voluntary, and patients provide a written informed consent for participation. The average response rate per year is $55 \% .^{33}$ The survey and the use of the data for purposes of secondary data analysis follow the requirements as defined by the German Social Code VI, IX and X. Since the data are fully anonymised, no additional ethical approval for the present analysis was necessary. ${ }^{34}$

For the current study, we used data from all 642 hospitals on 274513 individuals who underwent in-patient medical rehabilitation because of somatic disease during 2007-2011 .

\section{Measures}

Patients who participate in the survey are asked to report their satisfaction with different domains of the rehabilitation process by means of 40 items, most of which provide a 5-point Likert response format. The domains comprise the satisfaction with different aspects of care (see table 1 for an overview of exemplary questions). Additionally, survey participants are requested to provide an overall rating of their satisfaction with the rehabilitation they received. The different domains of patient satisfaction were operationalised in the same way that also the German Statutory Pension Insurance Scheme employs for its internal quality reports. The satisfaction with each domain was rated from 1 to 5 by calculating mean scores of the respective items of each scale with higher means indicating a greater satisfaction. Because the mean scores were highly left skewed, assumptions for linear regression were not fulfilled. We therefore decided to dichotomise the scores for purposes of analysis, with values $<4$ indicating a low or moderate satisfaction and values $\geq 4$ indicating a high satisfaction. This procedure is in line with other studies in the field. ${ }^{29}$

We excluded the domains 'recommendations received during the stay in the hospital', 'preparation for the time after discharge' and 'quality and comprehensiveness of services in the hospital' because they combined items with unequal response formats or had a low internal consistency (see table 1). Cronbach's alpha for the remaining 


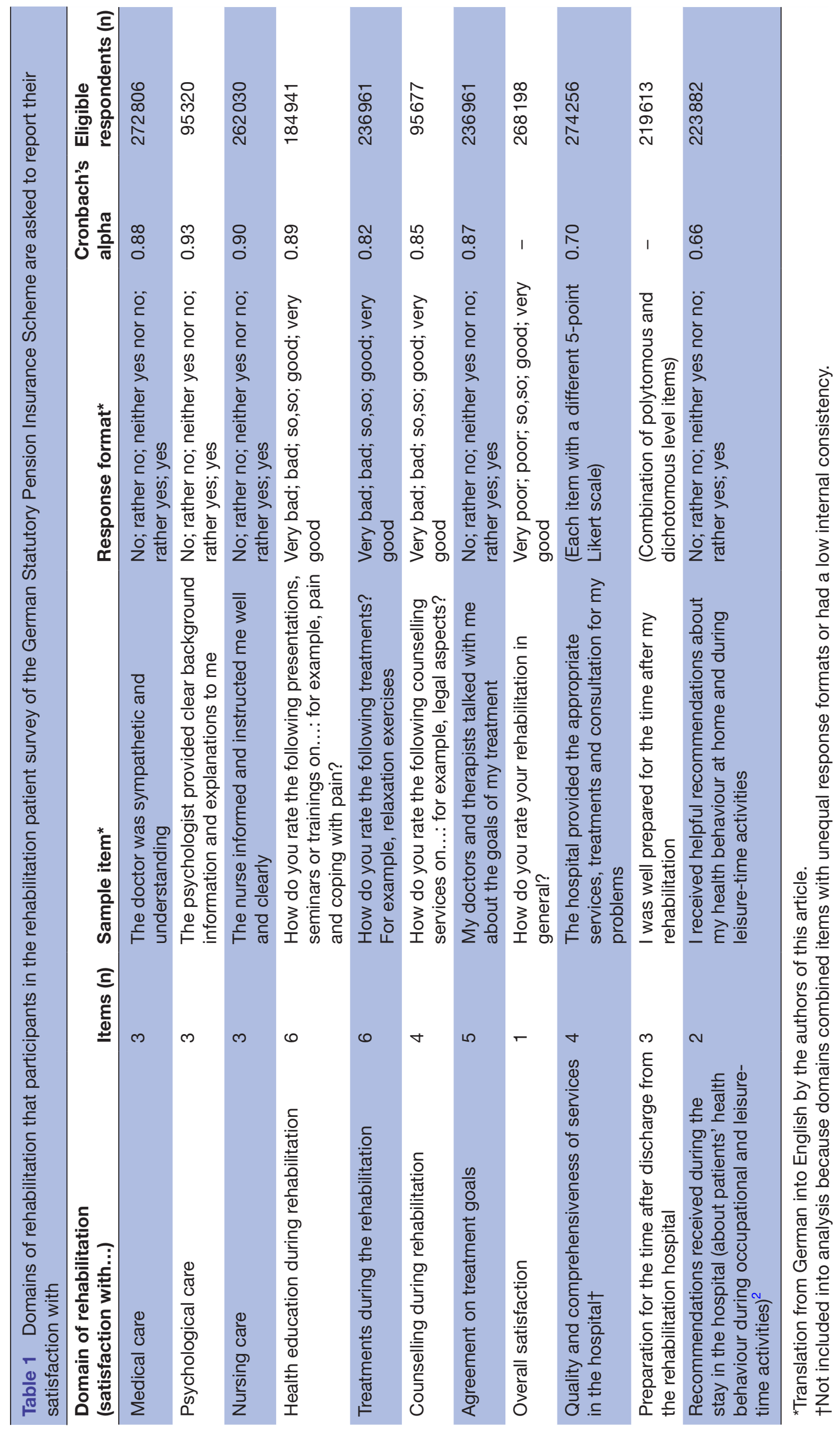


domains ranged between 0.82 and 0.93 , indicating satisfactory internal consistency. ${ }^{35}$

Since the range of treatment components that patients receive during rehabilitation varies between individuals (eg, not all patients receive psychological care during their stay), the available sample sizes differed for the eight domains of satisfaction, ranging between $n=95320$ for satisfaction with psychological care and $n=274256$ for satisfaction with the agreement on treatment goals.

Aside from a comparison of German and non-German nationals, the dataset allowed to stratify non-German nationality by four subgroups: Turkey, Former Yugoslavia, Portugal/Spain/Italy/Greece and 'other'. This stratification was chosen because it is the one used in other routine datasets from social security organisations in Germany and allows comparison with previous studies in the field. ${ }^{36}$

As relevant covariates, the dataset provided information on age (in years), sex, marital status (single/divorced/ widowed, married), education (low, intermediate, high, other/unknown), occupational position (skilled labour, semiskilled/unskilled labour, trainee/unemployed), on the type of somatic diagnosis on admission to rehabilitation (diseases of the skeletal system [ICD-10 codes M00-M99], neoplasms [ICD-10 codes C00-D48], diseases of the circulatory system [ICD-10 codes I00-I99], other) and on the time absent from work due to illness in the last 12 months before rehabilitation ( 0 months, $<3$ months, 3 to $<6$ months, $\geq 6$ months, not employed). Type of somatic diagnosis and time absent from work were considered as proxy variables for disease severity. We also took into account information on whether respondents received assistance in completing the self-administered questionnaire, which was regarded a proxy for German-language proficiency, for comprehensibility of the questionnaire and for other factors that limited patients in filling in the questionnaire on their own. ${ }^{37-39}$ Finally, we considered the type of rehabilitation (rehabilitation directly following a general hospital stay vs rehabilitation provided independently of a prior general hospital stay). All variables had less than $3 \%$ of missing values. Cases with missing values were deleted from the analysis (list-wise deletion). A sensitivity analysis that was conducted using multiple imputation did not reveal any relevant differences between analyses based on imputed versus non-imputed data.

\section{Statistical analysis}

We calculated descriptive statistics stratified by nationality for purposes of sample description using arithmetic means, SD and frequencies. Independent Student's t-tests and $\chi^{2}$ tests for independence, respectively, were used to statistically test for differences between the nationality strata.

To adjust for socioeconomic and health differences between the population groups, we calculated multivariable logistic regression models and controlled for the covariates described above. In order to allow comparisons of effect estimates across the eight different domains of satisfaction (outcomes), we computed average marginal effects (AMEs) instead of ORs. ${ }^{40}$ AMEs represent the change of the probability for the outcome by each unit increase of an independent variable with all other variables of the model being held constant and averaged across all respondents. ${ }^{41}$ We conducted a multilevel analysis to account for the fact that respondents were clustered within the 642 rehabilitation hospitals.

To account for multiple testing in the descriptive and multivariable comparison of the eight satisfaction scale scores across groups, we used a conservative significance level of $\alpha=0.05 / 10=0.005$. For this purpose, AMEs and their $99.5 \% \mathrm{CI}$ are provided for all multivariable models.

All analyses were performed using Stata $12 .{ }^{42}$

\section{RESULTS}

Data for 274517 individuals were available who completed an in-patient medical rehabilitation in the years $2007-2011$. Of these, $0.9 \%(n=2429)$ had a nationality from a former Yugoslavian country, $0.8 \% \quad(n=2301)$ were nationals from Turkey, $0.8 \%(\mathrm{n}=2180)$ held a nationality from the South European countries Portugal, Spain, Italy or Greece and $2.5 \%(\mathrm{n}=5244)$ were nationals from other countries. In total, $4.4 \%(n=12154)$ of the sample comprised individuals of non-German nationality.

Table 2 gives an overview of the sample characteristics stratified by nationality. Aside from a higher male-to-female ratio and a lower occupational position in non-German nationals, the population groups also differed with respect to their underlying diseases conditions. The proportion of individuals who rated their satisfaction with rehabilitation as low or moderate also differed between the population groups (table 3). As compared with Germans, Turkish nationals were less satisfied with all but one ('satisfaction with agreement on treatment goals') domain of their rehabilitation. Differences ranged between 5.5 ('satisfaction with psychological care') and 18.9 percentage points ('overall satisfaction with rehabilitation'). Rehabilitation patients with a nationality from a Former Yugoslavian country or from Portugal, Spain, Italy or Greece were equally satisfied with most of the domains of their rehabilitation as Germans. Lower satisfaction ratings as compared with Germans were only observed for the domain of treatments during rehabilitation and with respect to its overall evaluation. For the domains of psychological care and agreement on treatment goals, the proportion of poorly satisfied patients among non-Germans was significantly lower than among Germans.

Table 4 shows the results of the multivariable logistic regression models with low/moderate satisfaction with each of the eight dimensions as the dependent variable. The multivariable findings resemble the results of the descriptive analysis. As becomes evident, Turkish nationals had a higher probability for being less satisfied with all but two ('agreement on treatment goals' and 'medical care') domains of their rehabilitation, with AMEs ranging between 0.06 (99.5\% CI 0.03 to 0.09 ) for 


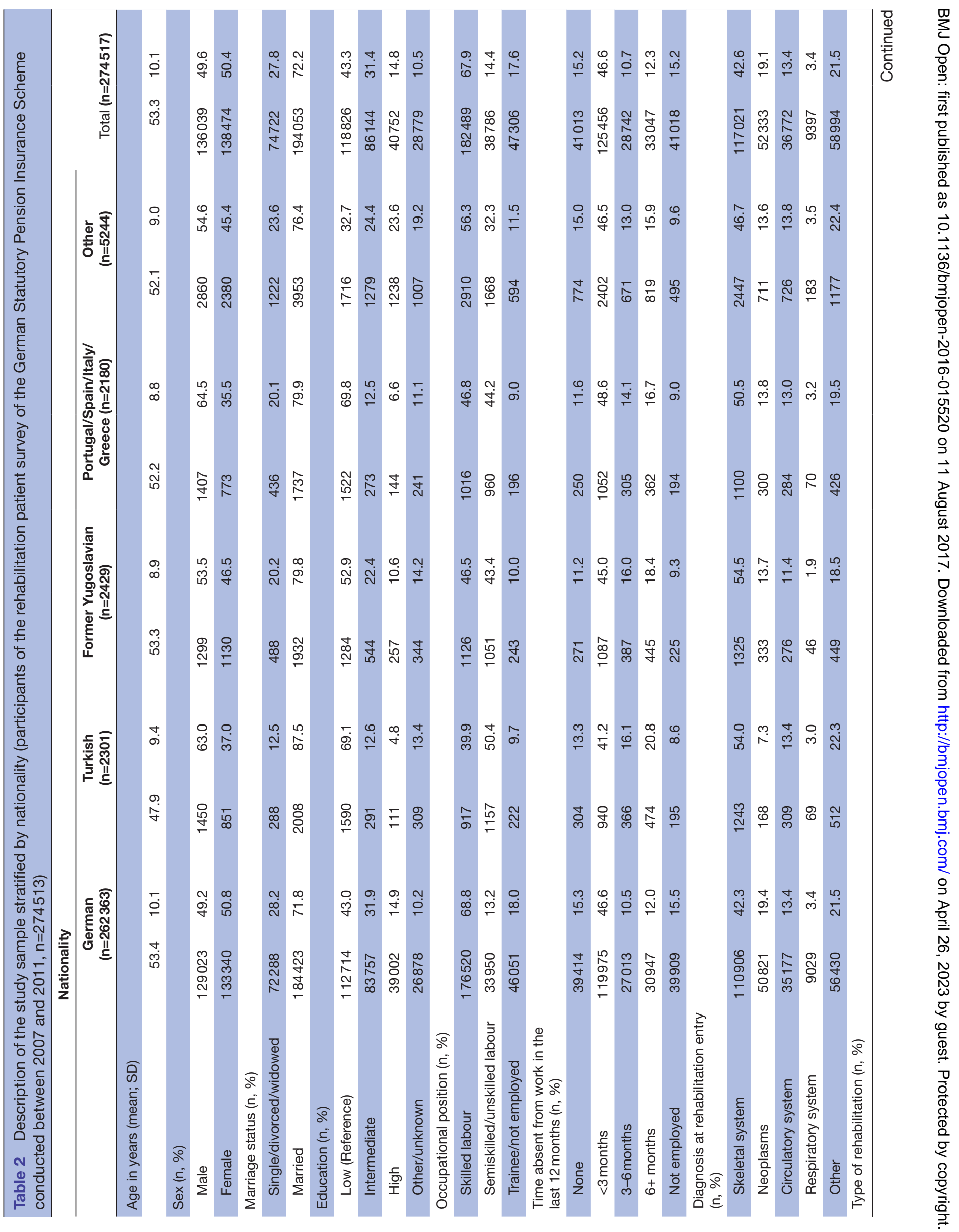




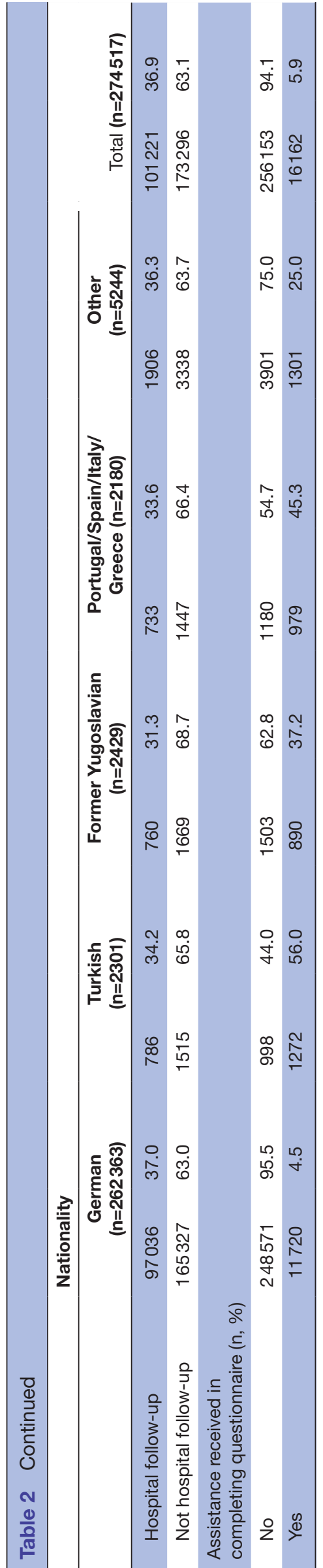

the domain of 'satisfaction with nursing care' and 0.12 (99.5\% CI 0.09 to 0.16 ) for the domain of 'satisfaction with treatments during the rehabilitation'. Rehabilitation patients with a nationality from a former Yugoslavian country or from Portugal, Spain, Italy or Greece were as equally satisfied with most aspects of their rehabilitation as Germans. A lower satisfaction rating for patients from Portugal, Spain, Italy or Greece was only observed for the domain of 'satisfaction with treatments during rehabilitation' (AME $=0.04 ; 99.5 \%$ CI 0.01 to 0.07 ). As compared with Germans, both population groups reported a higher satisfaction with psychological care (AME $=-0.05 ; 99.5 \%$ CI -0.09 to -0.01 and $\mathrm{AME}=-0.07 ; 99.5 \%$ CI -0.11 to -0.02 , respectively) and with the agreement on treatment goals $(\mathrm{AME}=-0.10 ; 99.5 \%$ CI -0.13 to -0.06 and $\mathrm{AME}=-0.05$; $99.5 \%$ CI -0.08 to -0.01 , respectively). In addition, patients from Former Yugoslavia reported higher satisfaction ratings with health education during rehabilitation (AME $=-0.04 ; 99.5 \%$ CI -0.08 to -0.01 ). Unlike for Turkish nationals, no differences in the overall evaluation of rehabilitation were observed between Germans and the other groups of non-German nationals.

Regarding the covariates the analysis was adjusted for, a shorter time of being absent from work, lower age, being married and undergoing treatment because of cancer were associated with higher satisfaction ratings for all domains of rehabilitation. For some domains, respondents who received assistance in completing the questionnaire provided higher satisfaction ratings than individuals who completed the questionnaire on their own. Individuals who attended rehabilitation as a follow-up treatment to their hospital stay reported higher satisfaction scores than patients whose rehabilitation was not related to a previous hospital stay. For most domains, no significant association between occupational position and satisfaction was observed.

\section{DISCUSSION}

Foreign nationals residing in Germany and other European countries, on average, have a lower utilisation of rehabilitation and benefit less from rehabilitative services than the respective majority population. Given the association of healthcare satisfaction and healthcare outcomes, knowledge about possible differences in the satisfaction between the foreign and autochthonous population can help to adjust rehabilitative care to the objective and subjective needs of the entire population. In this study, we examined the satisfaction with different aspects of the rehabilitative care process in Germans and non-Germans residing in Germany. We showed that Turkish nationals are less satisfied with almost all of the domains of rehabilitation studied. Similar observations were made in other healthcare settings in several European countries. ${ }^{29}$ We can confirm this finding for the field of rehabilitative care for Turks residing in Germany. In addition, our study shows that it is important to take into account the heterogeneity of the population in health services research. 


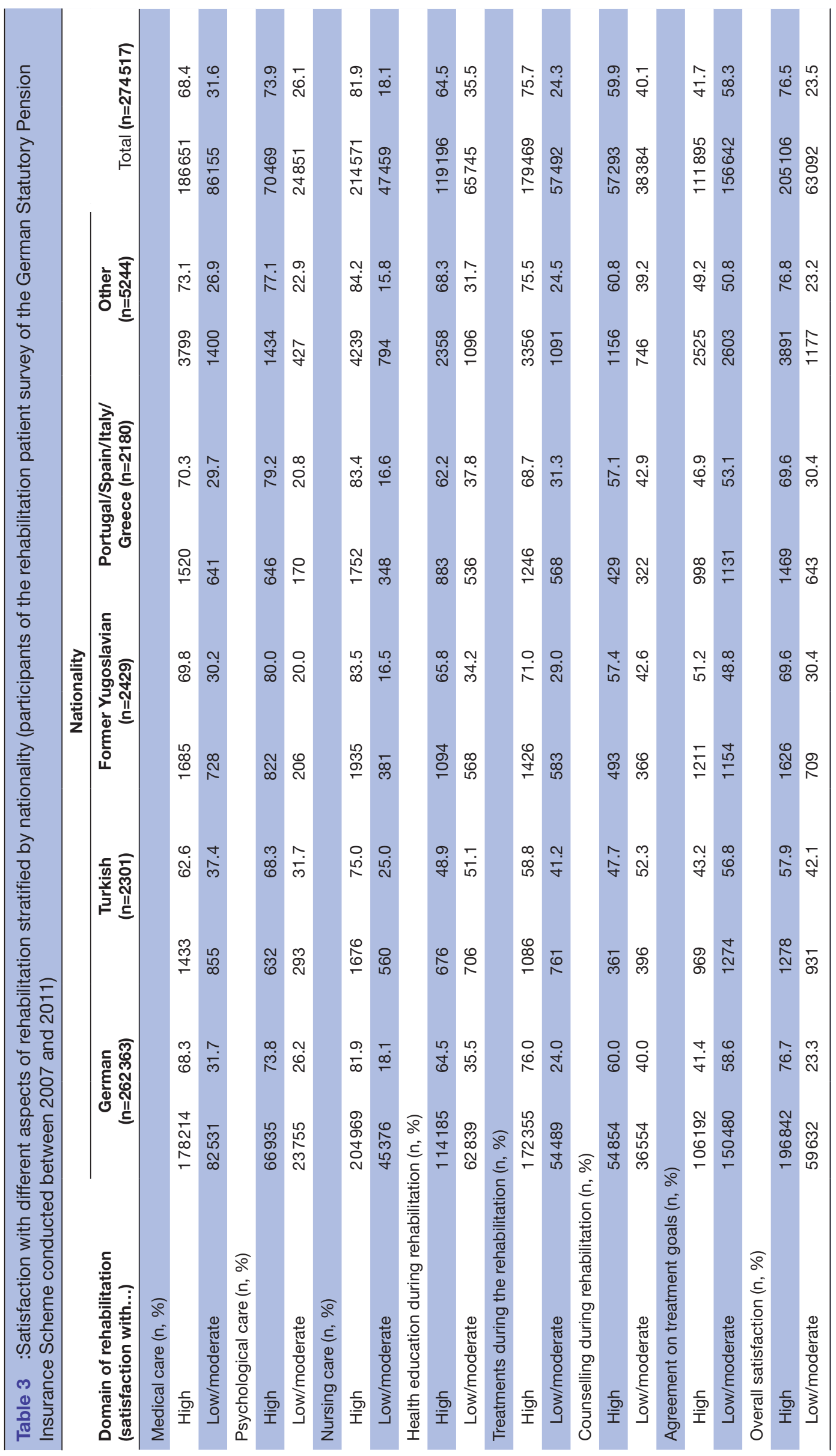




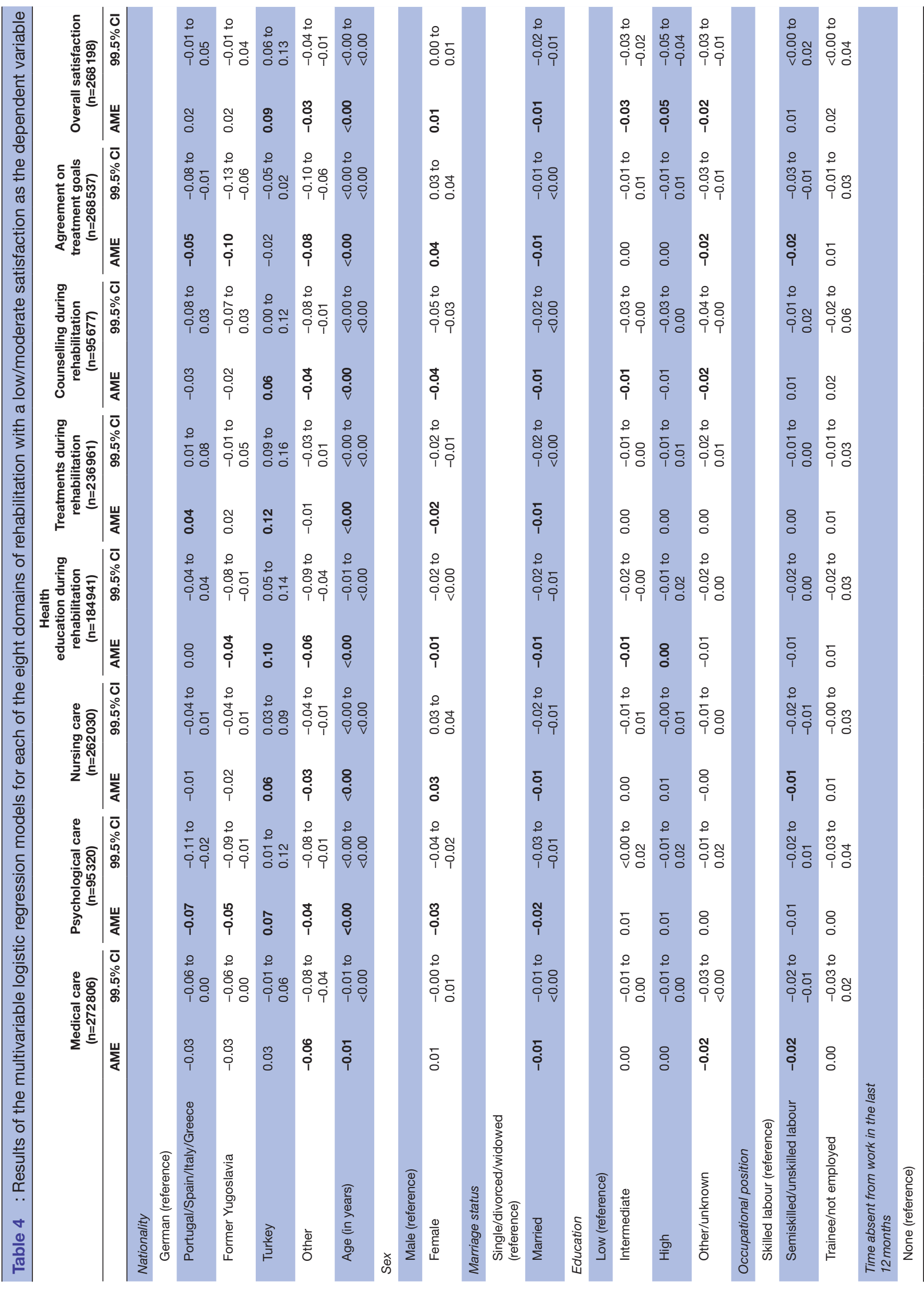




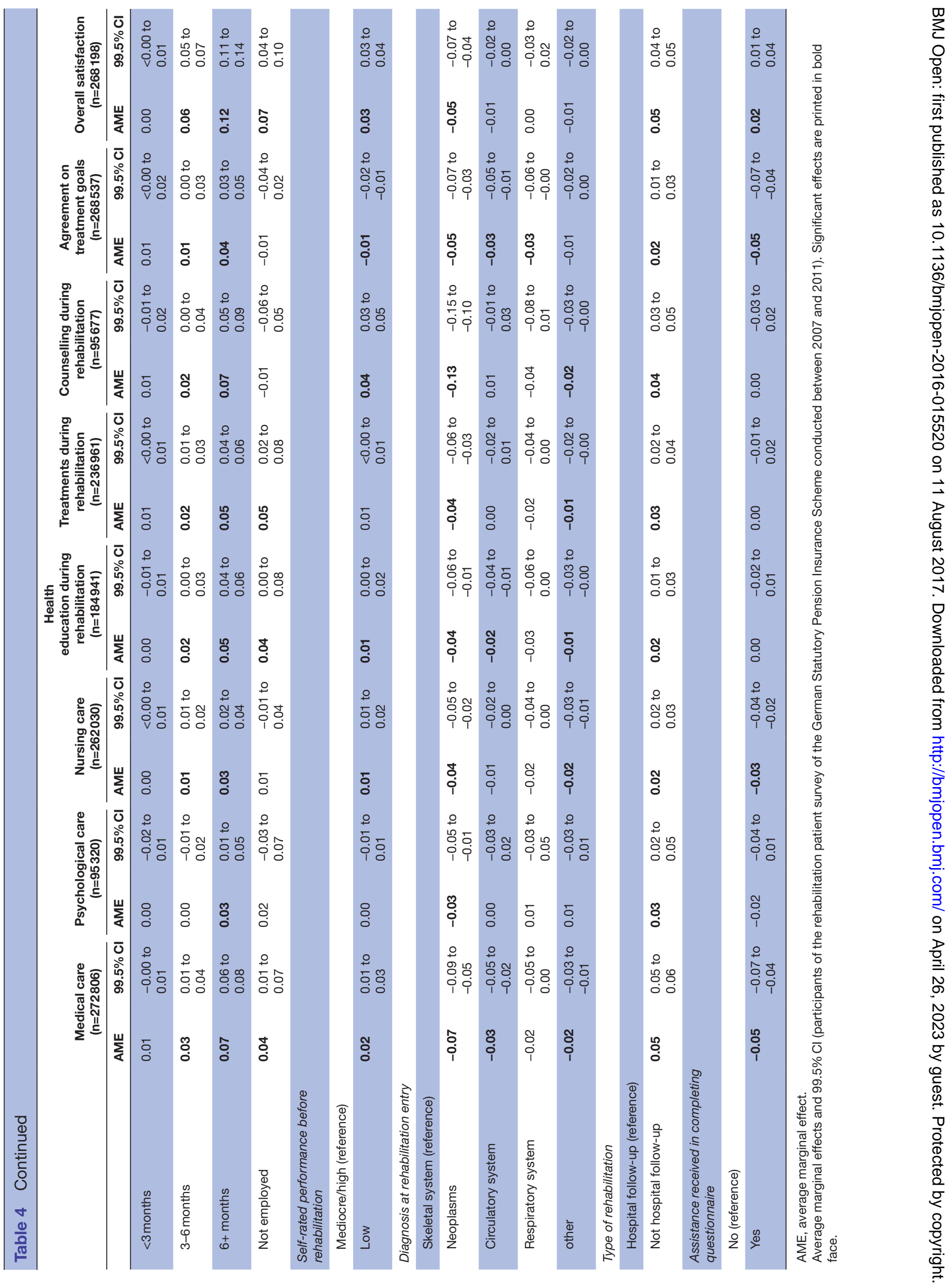


Unlike Turkish nationals, individuals originating from a Former Yugoslavian country or from Portugal, Spain, Italy or Greece were as satisfied as Germans with most aspects of their rehabilitation, including their overall evaluation of the services received. This suggests that rehabilitative care institutions in Germany are better able to meet the needs of these groups of migrants than they are for patients of Turkish origin.

To the best of our knowledge, the only quantitative investigation into the satisfaction of Turkish migrant patients in Germany has been conducted by Borde et $a^{31}{ }^{31}$ The authors studied 320 women of German and 262 women of Turkish origin with respect to their satisfaction with seven domains of obstetrics treatment at a large university hospital in Berlin, Germany. They found that women of Turkish origin were less satisfied with six of the seven domains studied, comprising medical, nursing and psychosocial care, the information received as well as food and accommodation provided during the stay.

In our study, comparably large differences between Turkish and German nationals in Germany could be observed for the satisfaction with health education and with treatments provided during the rehabilitation. In these two domains, the likelihood of a low or moderate satisfaction was 10 and 12 percentage points, respectively, higher among Turkish nationals than among Germans. This corresponds to findings from qualitative studies that focused on potential barriers that Turkish migrants may encounter in the rehabilitative system. ${ }^{20-22}$ These investigations showed that communication problems between patients and healthcare providers resulting from poor German language proficiency may interfere with an adequate provision of rehabilitation for patients of Turkish origin. Patients and providers reported that language problems make it difficult to instruct patients about therapies and to communicate with them during exercises. In addition, most hospitals are not able to offer information and education services in Turkish language, which is why Turkish patients usually attend German-language services. Because of low German language proficiency, some Turkish patients are not able to fully comprehend the content provided. This may result in a poor satisfaction with rehabilitative services. However, since we adjusted our multivariable analysis for German-language competency by means of a proxy variable and given the fact that only a German-language questionnaire was used, it is unlikely that the lower satisfaction with rehabilitation among Turks migrants may be fully explained by poor German language proficiency.

Aside from language proficiency, therefore, other explanatory factors for the low satisfaction in Turkish nationals need to be considered. Also, cultural and religious needs that are not sufficiently taken into account by rehabilitative care institutions may have a negative effect on the provision of rehabilitative care. ${ }^{21}{ }^{22}$ Apart from culture-specific illness perceptions, they comprise different cultural taboos such as exercising together with fellow patients from the opposite sex or being medically examined by health professional from the opposite sex. If health providers are not aware of these diverse expectations or neglect to deal with them appropriately, this may lead to frustration and poor satisfaction with the rehabilitative care received. Furthermore, Turkish migrants have been reported to be socially less integrated ${ }^{43}$ and to have stronger perceptions about being discriminated against ${ }^{44}$ than other groups of migrants in Germany, including people of South European and Former Yugoslavian origin. This can also affect the interaction within healthcare institutions and may limit perceived possibilities to communicate own expectations concerning healthcare. A lower satisfaction with healthcare in Turkish nationals may also be responsible for poorer rehabilitative outcomes in this population group that have been reported by other studies. ${ }^{13} 1617$

The association between low/moderate satisfaction and the sociodemographic variables that we took into account as covariates into our multivariable analysis are mostly in line with those identified in other studies on the satisfaction with healthcare services. ${ }^{45}{ }^{46}$ Depending on the underlying diagnosis, individuals had a higher or lower likelihood of a low satisfaction rating. This can be explained by the different treatment regimes that patients receive depending on their diagnoses as well as by differences in overall impairment. Notably, patients undergoing rehabilitation because of cancer reported a higher satisfaction than patient receiving treatment because of other conditions. This has also been observed in previous studies. ${ }^{47}$

\section{Strengths and limitations}

A strength of our study is the use of routine survey data from an internal quality assurance programme implemented by a large social security organisation in Germany, which accounts for the majority of rehabilitations provided in Germany. ${ }^{48}{ }^{49}$ The data can be considered to be of high quality as different measures of quality control are implemented in the survey including high standards for data protection. ${ }^{34}$

The present study also has some limitations. All patients randomly selected by the German Statutory Pension Insurance Scheme receive a German-language questionnaire and are invited to take part in the survey by means of a German-language invitation letter. It is likely that this approach leads to a selection bias among patients who are not fluent in the German language. We tried to adjust for this shortcoming by including information on assistance received in completing the questionnaire into the multivariable analysis following the approach of previous research. ${ }^{17}$ 37-3950 Still, it cannot be ruled out that patients with little proficiency of the German language interpreted questions differently than German nationals or did not respond to survey invitations at all. This may have distorted our findings and presumably also affects the sociodemographic composition of rehabilitation patients who took part in the survey. Although the sociodemographic composition within the five nationality 
strata of our sample corresponds to sociodemographic characteristics of all individuals who completed medical rehabilitation in the respective time period, the proportion of non-German nationals was lower than expected. In our sample, $0.9 \%, 0.8 \%$ and $0.8 \%$ of all individuals had a nationality from Former Yugoslavia, Turkey and Portugal/Spain/Italy/Greece, respectively. In contrast, of those who completed medical rehabilitation in the years 2007-2011, about $1.1 \%, 1.4 \%$ and $1.0 \%$ had a nationality from Former Yugoslavia, Turkey and Portugal/ Spain/Italy/Greece, respectively (data not shown). As becomes evident, the difference between the expected and observed proportion of non-German individuals in our sample is particularly pronounced for patients of Turkish origin. This may result from the fact that this population is particularly prone to low German language proficiency. ${ }^{51}$ Given the fact that those not fluent in the German language are underrepresented in our data and considering that poor language proficiency is a significant barrier in healthcare, ${ }^{21} 22$ our investigation likely underestimates the true difference in healthcare satisfaction between German and non-German nationals. The level of income as an important socioeconomic variable could not be taken into account as a covariate. Therefore, our results might be partially biased by residual confounding. We compared non-German and German nationals and because of limited information were not able to also take into account migrants who have a German citizenship (eg, foreign nationals who got naturalised after migrating to Germany or those who received German citizenship at birth as children born to non-German parents residing in Germany). This is a limitation frequently encountered in the analysis of routine data sets in Germany. ${ }^{36}$ However, we consider this to be a minor limitation since other studies in the field of rehabilitation that were able to also include the latter group of migrants showed that they experience similar barriers to healthcare access and effectiveness than non-German nationals. ${ }^{52}{ }^{53}$ We could not adjust for culture, religion, length of stay and acculturation in our analysis, which may be significantly related to patients' satisfaction with healthcare. ${ }^{30} 54$ Future studies should therefore also examine their role for differences in satisfaction between migrants and non-migrants in order to devise more adequate patient-oriented services for this population group.

\section{CONCLUSION}

Knowledge on the levels of patients' satisfaction with healthcare provision is important in order to adjust healthcare to their objective and subjective needs, to meet their expectations and to ensure a high standard of healthcare quality. Our study showed that Turkish nationals residing in Germany report a lower satisfaction with different components of medical rehabilitation than Germans. Rehabilitation patients of Former Yugoslavian or South European origin, in contrast, reported similar levels of satisfaction as the majority population.
The lower satisfaction observed in Turkish nationals may be attributable to cultural and religious needs not sufficiently addressed by healthcare providers. Also, a limited German language proficiency may be a significant barrier for communication in rehabilitation and may contribute to a lower satisfaction. This shows that migrants are a very heterogeneous population in terms of their expectations towards rehabilitation and emphasises the need for rehabilitative care institutions to provide services that are sensitive to the diversity of their clients.

One promising approach to deal with the heterogeneity of healthcare users in terms of expectations is diversity management. ${ }^{55}$ Diversity management could also address the fact that levels of healthcare satisfaction differ between migrants and non-migrants and vary between sociodemographic groups such as men and women and older and younger patients.

Contributors PB developed the concept and design of the study, performed the statistical analysis, interpreted the findings and drafted the manuscript. OS assisted in the statistical modeling of the data and in writing the manuscript. YYA and TW helped to interpret the findings. OR helped with the study design and data interpretation and critically revised the manuscript. All authors read and approved the final manuscript.

Funding The study was supported by a grant from the Association for Rehabilitation Research in North RhineWestphalia (Gesellschaft für Rehabilitationswissenschaften NordrheinWestfalen e.V.; GfR 12006) whose support we acknowledge. The publication costs of this article were funded by the German Research Foundation/Deutsche Forschungsgemeinschaft and the Technische Universität Chemnitz in the funding programme Open Access Publishing. The funders had no role in study design, data collection and analysis, decision to publish or preparation of the manuscript.

Competing interests None declared.

Patient consent The results presented in the manuscript are based on routine data from a social security institution that are made available for purposes of secondary data analysis. The survey is voluntary and patients provide a written informed consent for participation. The survey and the use of the data for purposes of secondary data analysis follow the requirements as defined by the German Social Code VI, IX and X. Since the data are fully anonymised, no additional ethical approval for the present analysis was necessary.

Provenance and peer review Not commissioned; externally peer reviewed.

Data sharing statement Data are available from the German Statutory Pension Insurance Scheme for researchers who meet the criteria for access to confidential data.

Open Access This is an Open Access article distributed in accordance with the Creative Commons Attribution Non Commercial (CC BY-NC 4.0) license, which permits others to distribute, remix, adapt, build upon this work non-commercially, and license their derivative works on different terms, provided the original work is properly cited and the use is non-commercial. See: http://creativecommons.org/ licenses/by-nc/4.0/

(C) Article author(s) (or their employer(s) unless otherwise stated in the text of the article) 2017. All rights reserved. No commercial use is permitted unless otherwise expressly granted.

\section{REFERENCES}

1. Rechel B, Mladovsky P, Ingleby D, et al. Migration and health in an increasingly diverse Europe. Lancet 2013;381:1235-45.

2. Statistisches Bundesamt. Bevölkerung und Erwerbstätigkeit. Bevölkerung mit Migrationshintergrund. Ergebnisse des Mikrozensus 2015 (Fachserie 1 Reihe 2.2) (Population and occupation. Population with a migration background. Findings from the microcensus 2015. Wiesbaden: Statistisches Bundesamt, 2016. 
3. Solé-Auró A, Crimmins EM. Health of Immigrants in European countries. Int Migr Rev 2008;42:861-76.

4. Razum O, Zeeb H, Meesmann U, et al. Migration und Gesundheit (Migration and health). Berlin: Robert Koch-Institut, 2008.

5. Brzoska P, Razum O. Migration and occupational health: high workrelated burden. Public Health Forum 2015;23:113-5.

6. Wasilkiewicz K, Albrechtsen E, Antonsen S. Occupational safety in a globalized construction industry: a study on Polish workers in Norway. Policy and Practice in Health and Safety 2016;14:128-43.

7. Guldenmund F, Cleal B, Mearns K. An exploratory study of migrant workers and safety in three European countries. Saf Sci 2013:52:92-9.

8. Spallek J, Zeeb H, Razum O. What do we have to know from migrants' past exposures to understand their health status? A life course approach. Emerg Themes Epidemiol 2011;8:6.

9. European Foundation for the improvement of living and working conditions. Employment and working conditions of migrant workers. Dublin: European Foundation for the Improvement of Living and Working Conditions, 2007

10. World Health Organization. World report on disability. Geneva: World Health Organization, 2011

11. Bengel J, Koch U, . Grundlagen der Rehabilitationswissenschaften: Themen, Strategien und Methoden der Rehabilitationsforschung (Basics of rehabilitation science: topics, strategies and methods of rehabilitation research)Berlin: Springer, 2000.

12. Gerdes N, Zwingmann C, Jäckel WH. The system of rehabilitation Germany. In: Jäckel WH, Bengel J, Herdt J, eds. Research in rehabilitation. Stuttgart: Schattauer, 2006:3-19.

13. Brzoska P, Voigtländer S, Spallek J, et al. Utilization and effectiveness of medical rehabilitation in foreign nationals residing in Germany. Eur J Epidemiol 2010;25:651-60.

14. Bozorgmehr K, Razum O. Effect of restricting access to health care on health expenditures among asylum-seekers and refugees: a quasi-experimental study in Germany, 1994-2013. Plos One 2015;10:e0131483.

15. Norredam M, Mygind A, Krasnik A. Access to health care for asylum seekers in the European Union-a comparative study of country policies. Eur J Public Health 2006;16:285-9.

16. Brzoska P, Razum O. Erreichbarkeit und Ergebnisqualität rehabilitativer Versorgung bei Menschen mit Migrationshintergrund (Accessibility and quality of rehabilitative services among migrants in Germany). BundesgesundheitsblattGesundheitsforschung-Gesundheitsschutz 2015;58:553-9.

17. Brzoska P, Sauzet O, Yilmaz-Aslan Y, et al. Self-rated treatment outcomes in medical rehabilitation among German and non-German nationals residing in Germany: an exploratory cross-sectional study. BMC Health Serv Res 2016;16:105.

18. Sloots M, Scheppers EF, Bartels EA, et al. First rehabilitation consultation in patients of non-native origin: factors that lead to tension in the patient-physician interaction. Disabil Rehabil 2009;31:1853-61.

19. Sloots $\mathrm{M}$, Dekker JH, Pont $\mathrm{M}$, et al. Reasons of drop-out from rehabilitation in patients of Turkish and Moroccan origin with chronic low back pain in The Netherlands: a qualitative study. J Rehabil Med 2010;42:566-73.

20. Schwarz B, Markin K, Salman R, et al. Barrieren für Migranten beim Zugang in die medizinische Rehabilitation der gesetzlichen Rentenversicherung [Barriers for migrants regarding the access to medical rehabilitation on behalf of the german pension insurance]. Die Rehabilitation 2015;54:362-8.

21. Brzoska $P$, Voigtländer $S$, Reutin $B$, et al; Rehabilitative Versorgung und gesundheitsbedingte Frühberentung von Personen mit Migrationshintergrund in Deutschland. Forschungsbericht 402 [Rehabilitative care and work-related disability among people with a migration background in Germany. Berlin: Bundesministerium für Arbeit und Soziales, 2010.

22. Brause M, Reutin B, Schott T, et al; Migration und gesundheitliche Ungleichheit in der Rehabilitation.Abschlussbericht (Migration and healthrelated inequalities in rehabilitation)Bielefeld: Universität Bielefeld 2010.

23. Barbosa CD, Balp MM, Kulich $\mathrm{K}$, et al. A literature review to explore the link between treatment satisfaction and adherence, compliance, and persistence. Patient Prefer Adherence 2012;6:39-48.

24. Säilä T, Mattila E, Kaila M, et al. Measuring patient assessments of the quality of outpatient care: a systematic review. J Eval Clin Pract 2008;14:148-54.

25. Hurwitz EL, Morgenstern H, Yu F. Satisfaction as a predictor of clinical outcomes among chiropractic and medical patients enrolled in the UCLA low back pain study. Spine 2005;30:2121-8.

26. Wickizer TM, Franklin G, Fulton-Kehoe D, et al. Patient satisfaction, treatment experience, and disability outcomes in a population-based cohort of injured workers in Washington State: implications for quality improvement. Health Serv Res 2004;39:727-48.

27. Richter M, Schmidt-Ott G, Ziele MF. Zielerreichung und Patientenzufriedenheit in der psychosomatischen Rehabilitation [Goals, goal attainment, and patient satisfaction in psychosomatic rehabilitation]. Zeitschrift für Psychosomatische Medizin und Psychotherapie 2011;57:91-9.

28. Bermejo I, Berger M, Kriston L, et al. Ist Patientenzufriedenheit in der stationären Depressionsbehandlung von der Qualität sprachlicher Deutschkenntnisse abhängig? [ls patients' satisfaction with inpatient depression treatment related to their German language proficiency?]. Psychiatrische Praxis 2009;36:279-85.

29. Mastaki JK. Migrant patients' satisfaction with health care services: a comprehensive review. Italian Journal of Public Health 2010;7:69-81.

30. Mead N, Roland M. Understanding why some ethnic minority patients evaluate medical care more negatively than white patients: a cross sectional analysis of a routine patient survey in English general practices. BMJ 2009;339:b3450.

31. Borde T, David M, Kentenich H. Erwartungen und Zufriedenheit deutscher und türkischsprachiger Patientinnen im Krankenhaus - eine vergleichende Befragung in einer Berliner Frauenklinik (What Turkish-speaking women expect in a german hospital and how satisfied they are with health care during their stay in a gynaecological hospital in Berlin - a comparative approach). Gesundheitswesen 2002;64:476-85.

32. Eriksen LR. Patient satisfaction with nursing care: concept clarification. J Nurs Meas 1995;3:59-76.

33. Widera T. Aktuelles aus der Reha-Qualitätssicherung-neue Ergebnisse der Rehabilitandenbefragung [Update from the quality assurance programme in rehabilitation. New findings from the rehabilitation patient survey. RVaktuell 2010;4/ 2010:153-9.

34. Deutsche Rentenversicherung. Handbuch zur Rehabilitandenbefragung. Befragung nach medizinischer Rehabilitation (Handbook on the rehabilitation patient survey. Survey following medical rehabilitation. Berlin: Deutsche Rentenversicherung Bund, 2012.

35. Tabachnick BG, Fidell LS. Using multivariate statistics. Boston: Pearson, 2010.

36. Brzoska P, Voigtländer S, Spallek J, et al. Die Nutzung von Routinedaten in der rehabilitationswissenschaftlichen Versorgungsforschung bei Menschen mit Migrationshintergrund: Möglichkeiten und Grenzen [The use of routine data to study rehabilitative care in populations with a migrational background: potential and limitations]. Gesundheitswesen 2012;74:371-8.

37. Dyar S, Lesperance M, Shannon R, et al. A nurse practitioner directed intervention improves the quality of life of patients with metastatic cancer: results of a randomized pilot study. J Palliat Med 2012;15:890-5.

38. Shinga-Ishihara $\mathrm{C}$, Nakai $\mathrm{Y}$, Milgrom $\mathrm{P}$, et al. Cross-cultural validity of a dietary questionnaire for studies of dental caries risk in Japanese. BMC Oral Health 2014;14:1.

39. Boynton PM, Wood GW, Greenhalgh T. Hands-on guide to questionnaire research: reaching beyond the white middle classes. BMJ: British Medical Journal 2004;328:1433.

40. Mood C. Logistic regression: why we cannot do what we think we can do, and what we can do about it. Eur Sociol Rev 2010;26:67-82.

41. Bartus T. Estimation of marginal effects using margeff. The Stata Journal 2005;5:309-29.

42. StataCorp. Stata Statistical Software: release 12. College Station: StataCorp LP 2011.

43. Noll H-H, Weick S. Zuwanderer mit türkischem Migrationshintergrund schlechter integriert. Indikatoren und Analysen zur Integration von Migranten in Deutschland [Immigrants with a Turkish migration background not so well-integrated: indicators and analyses of the integration of migrants in Germany]. Informationsdienst Soziale Indikatoren 2011;46:1-5.

44. Salentin K. Diskriminierungserfahrungen ethnischer Minderheiten in der Bundesrepublik [Discrimination experiences of ethnic minorities in Germany]. In: Groenemeyer A, Wieseler S, eds. Soziologie sozialer Probleme und sozialer Kontrolle: realitäten, Repräsentationen und Politik. Wiesbaden [Sociology of social problems and of social control: realities, representations and politics]: VS Verlag für sozialwissenschaften, 2008:515-26.

45. Lien E, Nafstad P, Rosvold EO. Non-western immigrants' satisfaction with the general practitioners' services in Oslo, Norway. Int $J$ Equity Health 2008;7:7:7.

46. Sixma HJ, Spreeuwenberg PM, van der Pasch MA. Patient satisfaction with the general practitioner: a two-level analysis. Sixma HJ, Spreeuwenberg PM, van der Pasch MA. Medical Care 1998;36:212-29. 
47. Meyer T, Pohontsch N, Maurischat C, et al. Patientenzufriedenheit und Zielorientierung in der Rehabilitation [Patient satisfaction and target orientation in rehabilitation]. Lage: Jacobs Verlag 2008

48. Widera T, Klosterhuis H. Patientenorientierung in der Praxis -10 Jahre Rehabilitandenbefragung im Rahmen der RehaQualitätssicherung der Rentenversicherung [Patient orientation in practice -10 years of the rehabilitation patient survey as part of the quality assurance programme of the German Social Insurance Scheme]. RVaktuell 2007;6:177-82.

49. Widera T, Beckmann U, Zander J, et al. Wer hat Recht-Rehabilitand oder KTL-Dokumentation [Who is right? Rehabilitation patient or KTL documentation?] RVaktuell 2011;10:298.

50. Meyer T, Deck R, Raspe H. Gültigkeit von Fragebogenangaben in der Rehabilitationsforschung: unter welchen Bedingungen füllen Patienten Fragebogen aus? [Validity of patient self report data in rehabilitation research: identifying circumstances of the patients' completion of questionnaires] Die Rehabilitation 2006;45:118-27.

51. Babka von Gostomski C. Fortschritte der Integration Zur Situation der fünf größten in Deutschland lebenden usländergruppen [Progress of integration. Situation of the five largest groups of non-German nationals living in Germany]. Bundesamt für Migration und FlüchtlingeNürnberg, 2010.

52. Voigtländer S, Brzoska P, Spallek J, et al; Die Inanspruchnahme medizinischer Rehabilitation bei Menschen mit Migrationshintergrund [Utilization of medical rehabilitation in people with a migration background]. In: Schott T, Razum O, eds. Migration und gesundheitliche ungleichheit in der Rehabilitation [Migration and health-related inequality in rehabilitation]. Weinheim: beltz Juventa, 2013:92-104.

53. Brause M, Reutin B, Razum O, et al. Rehabilitationserfolg bei Menschen mit türkischem Migrationshintergrund - Eine Auswertung von Routinedaten der Deutschen Rentenversicherungen Rheinland und Westfalen [Rehabilitation results of Turkish immigrants - an analysis of routine data from the Rhineland and Westfalia Pension Insurance]. Rehabilitation 2012;51:282-8.

54. Williams JA, Meltzer D, Arora V, et al. Attention to inpatients' religious and spiritual concerns: predictors and association with patient satisfaction. J Gen Intern Med 2011;26:1265-71.

55. Gordin J, Healthcare Din. In: borowski N, editor. Organizational Behaviour in Health Care. Sudbury: Jones \& Bartlett 2011:15-40. 